MATEC Web of Conferences 22,02020 (2015)

DOI: $10.1051 /$ matec conf/ 20152202020

(C) Owned by the authors, published by EDP Sciences, 2015

\title{
Literature Review on Reasons and Countermeasures on Large-scale Off-grid of Wind Turbine Generator System
}

\author{
Jun Zhu, Tianyu Liu* \& Qiyuan Huang \\ College of Electrical Engineering, Shanghai DianJi University, Shanghai, China
}

\begin{abstract}
This paper reviews the present situation of the application of wind turbines generator system(WTGS) at home and abroad, describes the strategic significance and the value of sustainable development of the wind power in the country, illustrates the problems, a variety of reasons and responses on large-scale off-grid of WTGS, compares the advantages and disadvantages of various methods, gives full consideration to the actual demand for WTGS works and characteristics and points out the further research.
\end{abstract}

Keywords: WTGS; off-grid; Dynamic reactive power compensation; Low voltage across

\section{INTRODUCTION}

In recent years, with the rapid depletion of fossil fuels such as coal and the increasing extrusion of environment problems, wind energy with the advantages of being clean and rich has developed rapidly. But because of the intermittent and discontinuity of wind power, the stability of power supply of power grid is greatly affected. And the off-grid of large-scale WTGS is the main problem for the utilization of wind power ${ }^{[1]}$. Therefore, this paper analyzes the causes and coping strategies on large-scale off-grid of wind turbine.

\section{REASONS ON LARGE-SCALE OFF-GRID OF WTGS}

Wind farm electric wiring ${ }^{[2]}$ is shown in Figure 1.

\subsection{WTGS reactive power management is imperfect}

After the resection of short-circuit fault, power grid voltage recovers gradually, but the fixed reactive power compensation equipment of wind turbines haven't completely run out, and it begins to output reactive power when the voltage is gradually recovered. At this time, although SVG, MCR and SVC reactive power equipment can be adjusted, but both adjustments of time constant are dissimilar. In the adjustment of process, if the response time is not enough, so under the influence of high and low voltage transformation, voltage stability and reliability will be threatened. The Intermittent and volatility of output power of wind farms have serious influence on the voltage stability of power system. It will lead to higher or lower generator terminal voltage of the machine and seriously will result in the loss of static voltage stability of system when the wind power system is weak and wind turbine generator system cannot provide or *Corresponding author: 738458910@,qq.com absorb enough reactive power to system. The solution to this problem is usually what we install capacitor group or static reactive compensation device on the wind farm bus and it can compensate the deficiency of the reactive power of wind turbine generator system [11-12]. Literatures [13-15] study this problem. Among them, literature [13] analyzes the reactive power limits of the wind farm based on doubly-fed electrical machine and put forward a kind of calculation method of reactive power limits of wind power system based on doubly-fed electrical machine. Literature [14] studies optimization model and algorithm of distribution network reactive power on the basis of considering the reactive power adjustment ability of wind farm based on doubly-fed electrical machine. Literature [15] discusses what the reactive power supply of wind farm based on doubly-fed electrical machine has important meaning when voltage rapidly drawdown and power grid operate steady. The control architecture of wind power system voltage reactive ${ }^{[3]}$ is shown in Figure 2.

\subsection{WTGS lacks low voltage crossing ability}

The loss of low voltage crossing ability is one of the main causes on large-scale off-grid of WTGS. Because of the loss of low voltage crossing ability, if power grid fails, the system voltage will drop to about $70 \%$ of the rated voltage, and then the WTGS will appears easily to take off the grid. Even some wind farm promise to possess low voltage crossing ability, but its low voltage crossing ability isn't debugged to open, and it lacks the certification testing of relevant departments, therefore it will also appear large-scale off-grid situation when the failure occurs. With the large-scale application of wind turbines, the research of fault ride-through ability of wind turbine is very important, literature [6] thinks that asynchronous wind turbines should have the ability of traditional synchronous generator, which can run without off-grid for power grid fault, can also participate in the control of 


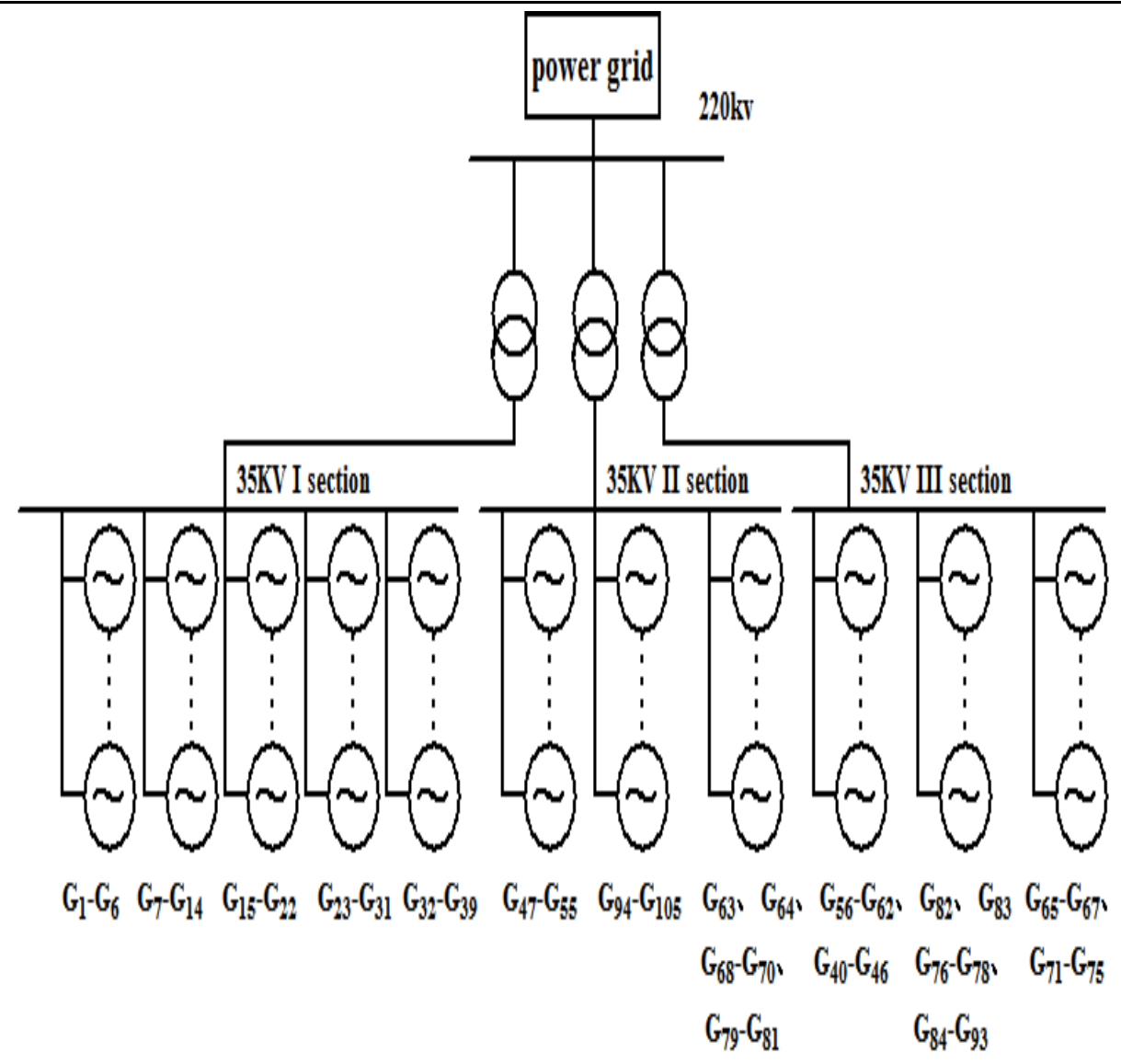

Figure 1. Wind farm electric wiring

voltage and frequency and has the capability of rapid removal of fault. Literature [7-10] researches low voltage ride-through technology of wind turbine. Literature [7] detailed analyzes the transient characteristics of three main models about the constant speed asynchronous wind turbines, synchronous direct-drive type wind turbines and doubly-fed wind turbines when the power grid voltage drops, summarizing the main LVRT scheme raised both at home and abroad and emphatically analyzes the LVRT plan about the toughest crossing ability of the doubly-fed wind turbine. Literature [8] discusses the influence that the doubly-fed wind turbines have on power system transient stability after it connects to grid. Literature [9] comes up with a novel rotor side protection circuit that can effectively restrain the increase of voltage of capacitors when the voltage drop in direct current side on the basis of discussing the model of electrical machine stability and transient mathematics. Literature [10] establishes a simplified DFIG low voltage ride-through system, conducts an experiment in 22 $\mathrm{KW}$ experiment platform. Last but not least, the results of the experiment show that CrowBar circuit can restrain the transient current in the stator and the rotor circuit of electrical machine and the system has the capability of low voltage ride-through. The require- ments of low voltage crossing ability on Chinese WTGS $^{[4]}$ is shown in Figure 3.

\subsection{WTGS protection does not conform to the grid adaptability}

On the one hand, the network protection configuration and WTGS constant value setting can't satisfy the normal operation needs, converter, WTGS and other equipment performance is good and bad are intermingled. Current transformer parameters and WTGS main control constant value can't cooperate with low voltage crossing ability, electrical protection can't coordinate with WTGS network protection, and the ability of resisting disturbance of operation of WTGS is low. On the other hand, wind farms' box-type transformer and step-up transformer tap position is unreasonable and can't match with each other. When the grid-connected node voltage of wind farm is kept within the scope of plus-minus $10 \%$ of nominal voltage, it can't guarantee the generator terminal voltage of each wind turbine within the scope of plus-minus $10 \%$ of rated voltage. Literature [16] analyzes the main influence of stability of power grid voltage around the main access points of wind farm that made up of doubly-fed electrical machine, discusses in detail the relationship between access capacity of wind 


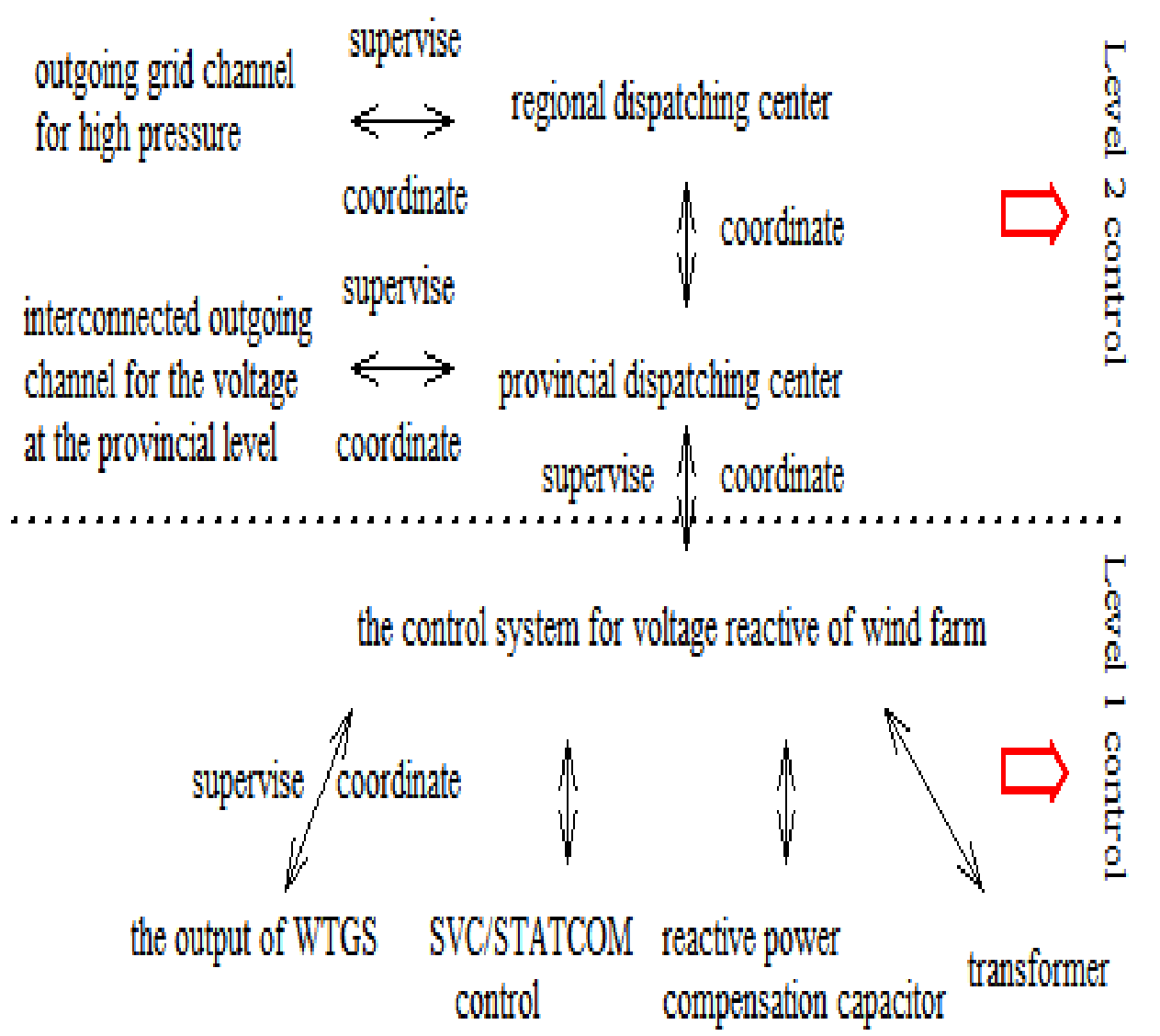

Figure 2. The control architecture of wind power system voltage reactive

farms and voltage stability, transient stability of power grid when large disturbances occur and low voltage ride-through ability of wind power appears. Finally it draws a conclusion that it is harmful to region voltage stability when the access capacity of wind farm is too big. Literature [17] discusses the transient case of generator terminal voltage of wind turbine when a fault happens in the power grid, but it doesn't discuss the change of the power grid voltage when wind turbines take off the net. Literature [18] illustrates the impact of the stability of power grid when wind power access to power grid depending on the case that wind power accesses to the local power grid In Hami, Xinjiang and puts forward the measures to improve the voltage quality in grid-connected area in view of the operation mode of local power grid. Literature [19] believes that the future research direction is the frequency stability, small interference stability of power grid after the large-scale wind power is connected to the power grid and the effect the characteristics of low voltage ride-through of WTGS have on the stability of the electric. Off-grid time-series of wind farm ${ }^{[2]}$ is shown in Table 1.

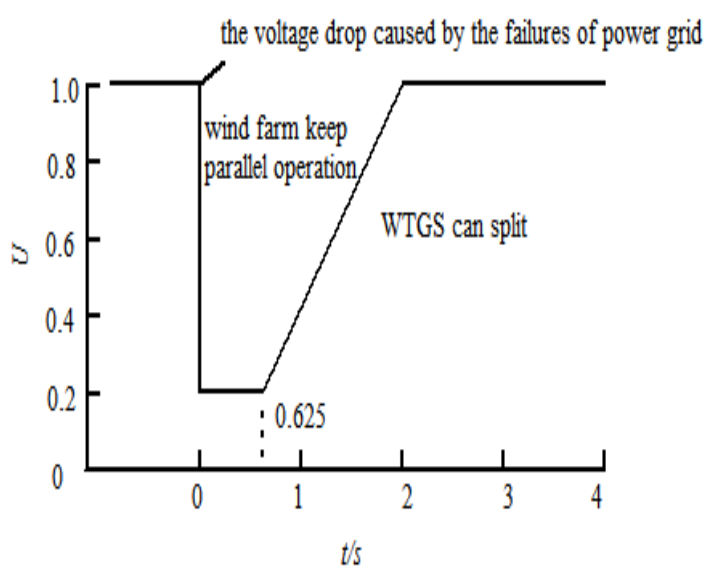

Figure 3. The requirements of low voltage crossing ability on Chinese WTGS

2.4 Wind farm construction and operation management level is not scientific

Wind farm constructions have many quality problems part of the project construction quality inspection ${ }^{[20]}$ control and test system implementation do not reach 
the designated position, the design principles and depth of electric part of wind farm are not unified and wind farm repeats similar failures. Wind farm operation management has weak link, the safety management system is not sound, field operation regulations are imperfect, reactive power and secondary system management can't meet the security requirements of power grid, and electric power dispatching institution does not check protective fixed value (voltage, frequency protection) of wind farm, without effective supervision and management on the wind farm reactive power compensation device configuration and parameter setting ${ }^{[21]}$. The power grid connection diagram of off-grid wind farm is shown in Figure 4.

Table 1. Off-grid time-series of wind farm

\begin{tabular}{ll}
\hline Time/s & wind turbine action events \\
\hline 1.7669 & No.65-67,71-75 off-grid \\
1.7844 & No.18-24,63,64,68 off-grid \\
1.8084 & No.4-6,10-17,25-35,40-46,53-62,6 \\
& $9-70,79-83$ off-grid \\
1.8093 & No.51,52 off-grid \\
1.8333 & No.1-3,7-9,36-39,47-50,76-78 \\
& off-grid \\
1.8588 & No.84 off-grid \\
1.8854 & No.85-93 off-grid \\
1.9074 & No.94-105 off-grid \\
\hline
\end{tabular}

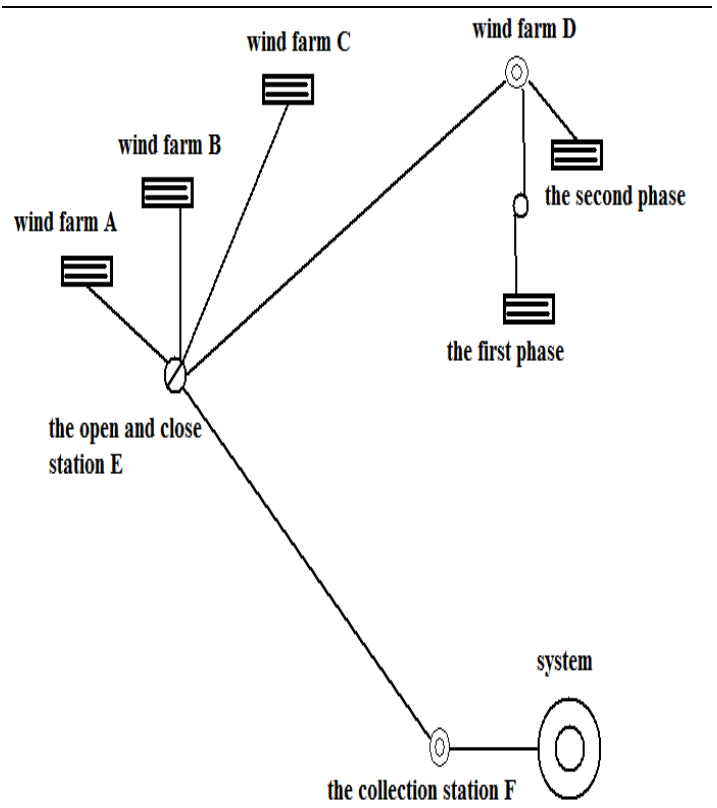

Figure 4. The power grid connection diagram of off-grid wind farm

\section{WTGS LARGE-SCALE OFF-GRID RESPONSE}

3.1 To strengthen the performance of the dynamic reactive power compensation device of WTGS

Wind farm should inspect the configuration ${ }^{[22]}$ and performance of reactive power compensation device combined with its own condition. If the dynamic reactive power adjustment ability of wind farm does not accord with standard, timely and effective measures should be taken to rectify it. The inductive reactive power capacity and exportable largest capacitive of dynamic reactive power compensation device should be strictly ensured in accordance with the principle of the balance of reactive power layering and partition, the general control of response time of dynamic adjustment is kept within $30 \mathrm{~ms}$. Effectively coordinate WTGS high voltage crossing ability and device response speed, and then WTGS will not meet off-grid because of the high voltage, so as to ensure the stability of the whole power supply ${ }^{[23]}$. Emergency reactive voltage control process is shown in Figure 5.

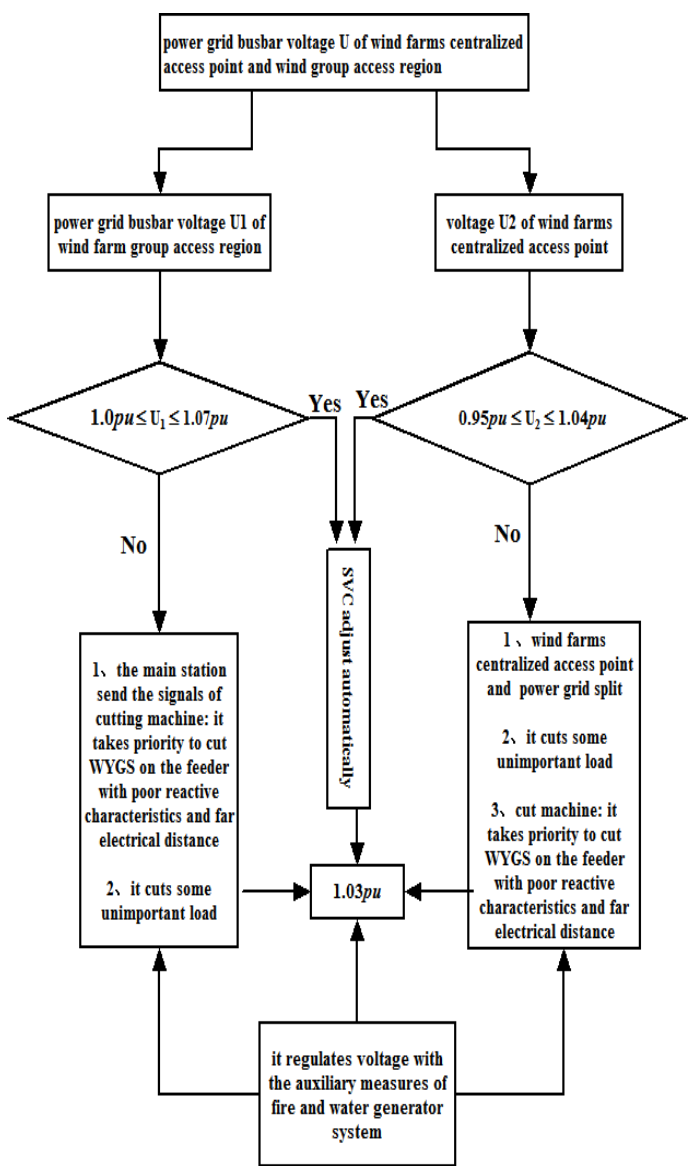

Figure 5. Emergency reactive voltage control process 


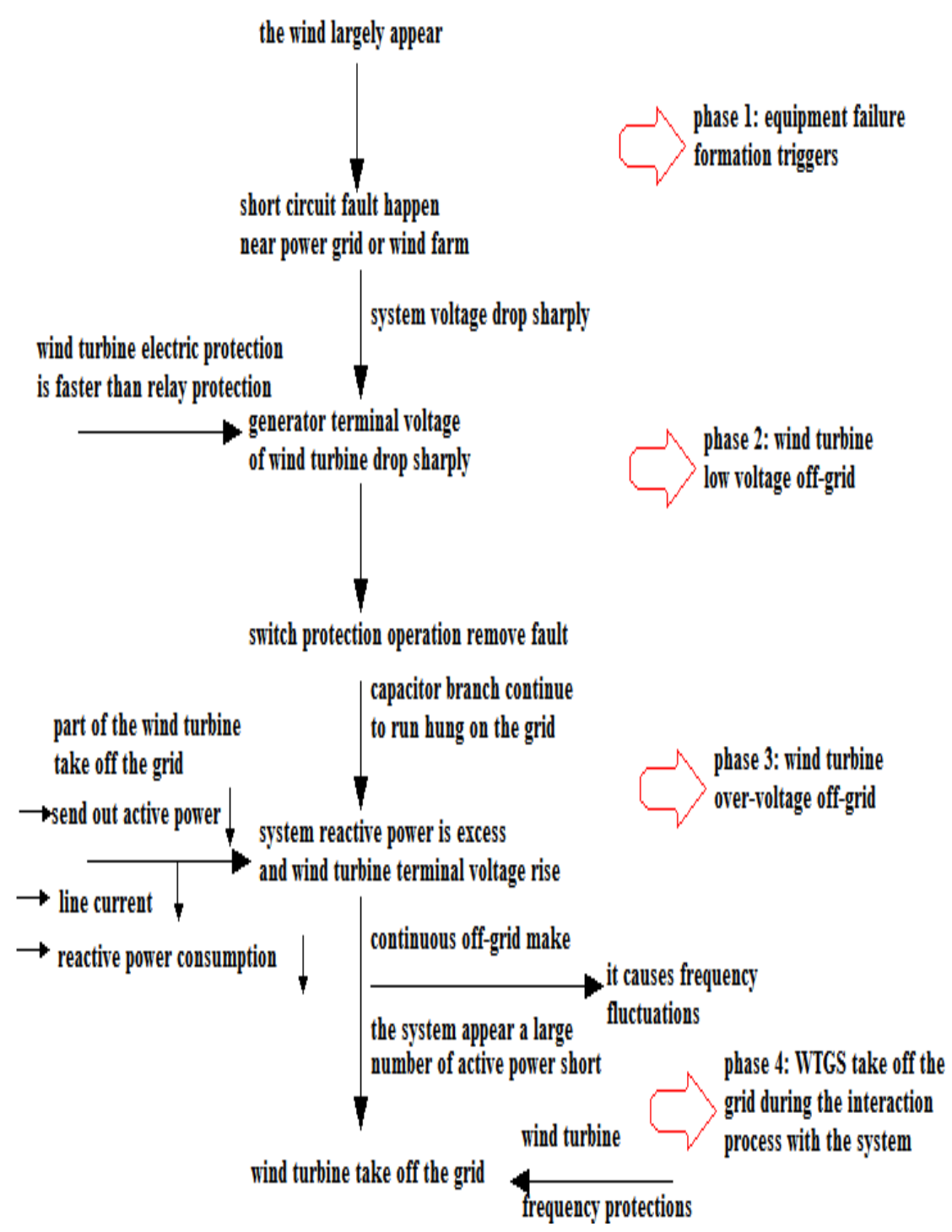

Figure 6. Four phases under wind turbine cascading triping-off 3.2 To ensure the low voltage crossing ability of
wind turbines

By analyzing the off-grid fault of WTGS, the ascensional range of voltage of power grid and generator terminal are usually 1.2 1.3Un. If most of the unit's ability to across high voltage is higher than the range, then even some off-grid units appear because of exceeding the range of low voltage crossing or not having low voltage crossing ability. So when the voltage instantaneously rises ${ }^{[24]}$, these parts of the unit can usually effectively balance their active and reactive power. Therefore, in order to effectively control the entire power grid voltage, we must ensure that the low voltage crossing ability of WTGS to meet the requirements ${ }^{[25]}$.
3.3 To strengthen the management of WTGS grid-connected detection and protection

WTGS grid-connected detection include low voltage crossing, power quality, grid adaptive testing ${ }^{[26]}$, active/reactive power regulation ability and the electrical model validation, and so on. Wind power grid-connected detection usually adopts the way of combining field sampling and type testing ${ }^{[27]}$, and the testing institution shall obtain authorization of competent department of the government. Wind farms and the protection of the WTGS shall be coordinated with joint system and shall not be conflicting with adaptability requirements of frequency, voltage and power quality. Four phases under wind turbine cascading triping-off are shown in Figure 6. 


\subsection{To strengthen the wind power dispatching opera- tion management}

When the wind farm submits grid-connected application for the first time to the dispatching agency, it should submit grid-connected detection report, key parts information, parameter purchase list of the WTGS and verified wind turbine electric model ${ }^{[28]}$ assemble line system parameters, all levels of boost variable parameters, reactive power compensation device parameter and control model and the whole active power/reactive power adjustment ability test report. Improved functional configuration of automatic reclosing for wind farm is shown in Figure 7.

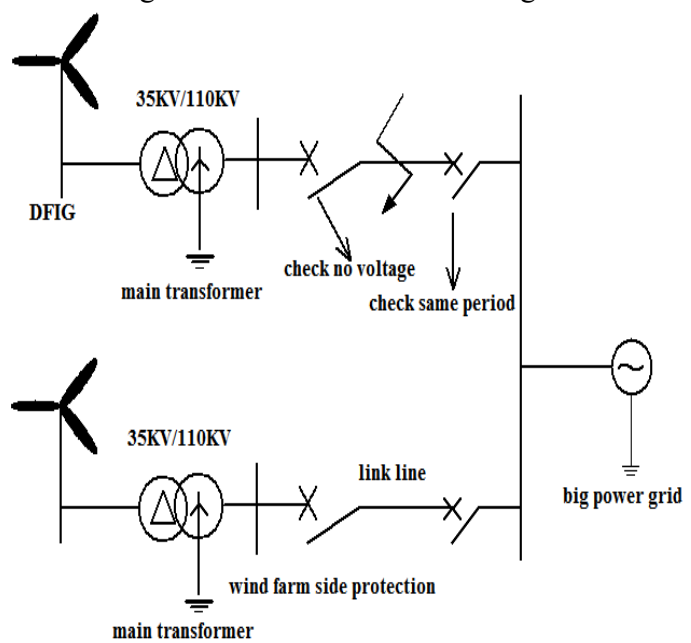

Figure 7. Improved functional configuration of automatic reclosing for wind farm

\section{FOLLOW-UP STUDIES OF LARGE-SCALE OFF-GRID OF WTGS}

The proportion of doubly-fed type and permanent magnet direct-drive type generators in power grid increases year by year ${ }^{[29]}$. For these WTGS with complex control system and control strategy, their fault current is closely related to the control strategy, the control of the unit is inevitably involved in relay protection. When manufacturing enterprise is unable to provide complete control strategy, we should organize forces to strengthen cooperation and establish a general simulation model to own the convenience of relay protection setting and performance analysis ${ }^{[30]}$. It is also helpful for quickly removing faults and plays an important role on the stability of power grid. We should also strengthen the research of wind turbines' fault characteristics and develop the research of wind turbines electromagnetic transient universal model. These have very important significance on the research of large-scale wind turbines off-grid accident.

\section{CONCLUSION}

In recent years many large-scale WTGS off-grid accidents occurred in our country and a lot of main problems exist in current wind power grid-connected operation. We should actively explore the relevant countermeasures, so as to promote the large-scale development of wind energy application in our country, effectively solve the problems of energy shortage, environment pollution and so on and achieve energy conservation and emission reduction targets.

\section{ACKNOWLEDGEMENT}

This work was supported by Shanghai Municipal Natural Science Foundation (No.14ZR1417200, No.15ZR1417300, No.12ZR1411600), Innovation Program of Shanghai Municipal Education Commission (No.14YZ157, No.15ZZ106), and Science and Technology Project of Minhang District (2014MH166).

\section{REFERENCES}

[1] Ye Xi, Lu Zongxiang. \& Qiao Yin, etc. 2012. Large-scale Wind Turbines to Take Off the Chain Network Accident Mechanism. Power System Automation 36(8): 11-17.

[2] Yang Jingang, Wu Linlin. \& Liu Hui, etc. 2013. Large-scale Wind Turbines Wind Power Pool Area High Voltage Network Mechanism. China Power (5): 154-155.

[3] Engelhardt S, Erlich I. \& Feltes C, etc. 2011. Reactive Power Capability of Wind Turbines Based on Doubly fed Induction Generators. IEEE Transactions on Energy Conversion 26(1): 364-372.

[4] He Shien. \& Dong Xinzhou. 2012. Large-scale Wind Turbines to Take off the Network Analysis of the Causes and Countermeasures. Power System Protection and Control 40(1): 131-138.

[5] Yang Fan, Song Yunting. \& Zhao Shuqiang. 2013. Large-scale Wind Turbines Chain Network Simulation Analysis and Countermeasures. Power Science and Engineering. 29(1): 21-26.

[6] Salman S K. 2004. Modelling Wind Turbine-generators for Fault Ride-through Studies. Universities Power Engineering Conference. 634-638.

[7] Zhang Xing. \& Zhang Longyun. 2008. Low Voltage Ride Through Technologies in Wind Turbine Generation. Proceedings of the CSU-EPSA. 20 (2): 1-8.

[8] Wu Lei. \& Xia Nan. 2011. Research on the Low Voltage Ride Through of DFIG for Wind Generating. Power Electronics. 45(6): 20-22.

[9] Li Jianlin, Liang Liang. \& Xu Honghua. 2008. Research on Low Voltage Ride Through Characteristics of Doubly Fed Induction Generator Based on Wind Power System. Power System and Clean Energy. 24(1): 39-43. 
[10]Liang Liang, Li Jianlin. \& Xu Honghua. 2008. Research on Low Voltage Ride Through of Double Fed Inductive Generator Wind Power System. Power Electronics. 42(3): 19-21.

[11]He Yikang. \& Hu Jianbin. 2005. Modeling and Control of Wind Turbine Used DFIG Under Network Fault Conditions. Electrical Machines and Systems. 986-991.

[12]Li Ran. \& Tang Fan. 2012. A New Scheme of Reactive Power Compensation and Voltage Control for DFIG Based Wind Farm. Proceedings of the CSEE. 32(19): 16-23.

[13]Lang Yongqiang. \& Zhang Xueguang. 2007. Reactive Power Analysis and Control of Doubly Fed Induction Generator Wind Farm. Proceedings of the CSEE. 27(9): 77-82.

[14]Zhao Jingjing. \& Fu Yang. 2011. Reactive Power Optimization in Distribution Network Considering Reactive Power Regulation Capability of DFIG Wind Farm. Automation of Electric Power Systems. 35(11): 33-37.

[15] Engelhardt S. \& Erlich I. 2011. Reactive Power Capability of Wind Turbines Based on Doubly Fed Induction Generators. IEEE Transactions on Energy Conversion. 26(1): 364-372.

[16]Zou Zhixiang. \& Zhou Keliang. 2011. Analysis on Influences of Grid-connected Wind Farm on Voltage Stability of Local Power Network Neighboring to Connection Point. Power System Technology. 35(11): 50-56.

[17]Zhang Feng. \& Li Mingxia. 2011. Transient Voltage Stability Study about a Regional Grid Integrated with Wind Power. Electric Power. 44(9): 17-21.

[18]Li Qiang. \& Li Fengting. 2012. Voltage Influence of Wind Power Integration. Electric Power. 45(4): 15-18.

[19]Chi Yongning, Liu Yanhua. 2007. Study on Impact of Wind Power Integration on Power System. Power System Technology. 3(3): 77-81.

[20] Gu Junhe, Liu Jianping. \& Jiang Hao. 2015. Literature Review on the Influence of Wind Power on System Frequency and Frequency Regulation Technologies of Wind Power. 32(1): 46-51.

[21]Ruttledge L, Miller N W, O’ Sullivan J. \& Flynn D. 2012. Frequency response of power systems with variable speed wind turbines. IEEE Transactions on Sustainable Energy. 4(3): 683-691.

[22] Vidyanandan K V. \& Senroy N. 2013. Primary frequency regulation by deloaded wind turbines using variable droop. IEEE Transactions on Power Systems. 28(2): 8 37-846.

[23] Wang Y, Delille G. \& Bayem H, etc. 2013. High wind power penetration in isolated power systems-assessment of wind inertial and primary frequency responses. IEEE Transactions on Power Systems. 28(3): 2412-2420.

[24]Tian Shuxin, Cheng Haozhong, Zeng Pingliang, Zhang Libo, Ma Zeliang, Hong Shaoyun, Zhang Jianping. \& Masoud Bazargan. 2014. Review of Transmission Planning for Integrating Large Clusters of Wind Power. Proceedings of the CSEE. 34(10): 1566-1574.

[25] Wan Zhendong. 2012. Flexible transmission system expansion considering accommodation capacity of large scale wind power. Shanghai: Shanghai Jiao Tong University.
[26] Xiao Chuangying, Wang Ningbo. \& Zhi Jing, etc. 2012. Power characteristics of jiuquan wind power base. $A u$ tomation of Electric Power Systems. 34(17): 64-67.

[27]Huang Yuchun, Yang Jiajia. \&Wen Fushuan, etc. 2013 Transmission system planning considering the capability of accommodating intermittent generation sources. $\mathrm{Au}$ tomation of Electric Power Systems. 37(4):28-34.

[28]Zhang Xinyan, Meng Ruilong, Mei Shengwei, Wang Weiqing. \& Yang Wenjing. 2015. Impact on HVDC Systems by the Sending AC System with Large-scale Wind Farms. High Voltage Engineering. 41(3): 730-738.

[29]Liu Xin, Zheng Tao, Huang Shaofeng. \& Yang Guosheng. 2015. Analysis on solution of cascade failure caused by automatic reclosing. Power System Protection and Control. 43(5): 51-56.

[30]Zheng Tao, Wei Zhanpeng. \& Li Juan, etc. 2014. Unsymmetrical short circuit current analysis of doubly fed induction generators with crowbar protection. Power System Protection and Control. 42(2): 7-12. 